\title{
Vocabulary Learning on Learner-Created Content by Using Web 2.0 Tools
}

\author{
Omer Eren \\ Gaziantep University, Turkey
}

\begin{abstract}
The present research examined the use of Web 2.0 tools to improve students' vocabulary knowledge at the School of Foreign Languages, Gaziantep University. Current studies in literature mostly deal with descriptions of students' attitudes towards the reasons for the use of web-based platforms. However, integrating usual classroom environment with Web 2.0 tools for specific sub-skills has not been examined much. It is aimed to contribute by investigating the feasibility of those tools as a supplement for vocabulary learning. This is an experimental research supported with semi-structured interviews and field notes. A pre-test and a post-test were administered to an experimental and a control group, and results were analyzed with the independent samples t-test. Following the post-test, semistructured interviews were conducted with 18 students in the experimental group. The analyses of the test results demonstrated that both groups had gains but the mean of the experimental group was higher, and this difference was statistically significant. Findings suggest that almost all students have positive attitudes towards the educational use of Web 2.0 tools.
\end{abstract}

Keywords: Web 2.0; Social networking; Learner created content; Vocabulary learning; Computer-assisted language learning.

\section{Introduction}

The use of technology in almost every aspects of our life brings out the question of how we can benefit from it in the best way. The 'new' technology as we have named it is no longer new to our students. When we try to use technological devices in our classrooms to make our classes more appealing for students, we probably forget the fact that they are born into this technology and the devices that make us excited can be something ordinary for our students. Although today's teachers are in a transition period from traditional classroom teaching with a chalk and a board into the use of smart boards, our learners are already engaged with surrounding technology and they are inevitably labeled as digital natives by Prensky (2001).

The rise of the use of internet has enabled learning to escape from the boundaries of usual classroom environment in which learners have to attend for long hours. Development of computer technology and expansion of personal computers paved the way for the use of internet by millions of people worldwide. In language teaching and learning, web presents an ocean of information for improving language skills. It is possible to find examples for every subject that is taught in classroom.

More or less, there has always been a generation gap between teachers and students but today this gap seems so big with dazzling improvements in the technology. English teachers 
have been using computers as a supplement to classroom since late 1960's. The era began with integrating computers as drill machines for pronunciation, grammar and vocabulary activities. Nowadays, we are witnessing that computer technology has made incredible improvements. The internet enabled everyone, especially students to reach information quickly on a global scale. Although we know the importance of the web, we see that web itself is in transformation as well.

\section{Web as an Interactive Tool}

The expansion of the web access has paved the way for the changes in the structure of the web. Web 1.0 presents information like a course book or an overhead transparency in which information is largely controlled by hosts or content providers (Wallace, 2004, p. 449). Users mostly read and obtained information from static websites. The interaction was quite limited with simple forums, and websites were browsed and designed as authenticated source of knowledge. Thus, this phase of the web resembled to an encyclopedia that was read on the screen instead of reading over a hardcover (Cormode \& Krisnamurthy, 2008). While Web 1.0 presented the knowledge as an extension of the traditional one way interaction, from content provider to user, Web 2.0 enabled a mutual interact with host and users. Web 2.0 is described as web-based applications and services that provide users interactive information together with visual, textual and audible communication (Akcay \& Arslan, 2010; Baird \& Fisher, 2005; Chan \& Cmor, 2009; Cullen, Kullman, \& Wild, 2013; George \& Dellasega, 2011).

The foremost stunning characteristics of Web 2.0 technology can be described as participatory, collaborative and distributed practices; in other words, relationship technologies, participatory media and social digital technologies (Greenhow, Robelia, \& Hughes, 2009). Unlike Web 1.0, users are as important as content providers in Web 2.0 through which mutual interaction is established. It enables internet users to participate in different communities and share their knowledge with each other. The main affordances for this innovative technology are depicted as creating user-defined linkages between users and content, sharing multimedia content through simple mechanisms like blogs.

Dede (2008) points out that 'knowledge' on Web 2.0 environment is a collective agreement and the validity of this knowledge is established through peer review in an incorporated community, knowledge is decentralized, accessible co-constructed among users (p. 80). Web 2.0 tools allow people to produce, consume and share information globally by allowing them, learners in particular, to create their own networks for feedback and support. One other feature of Web 2.0 is its feasibility for working on the created content. This is a very important feature permitting to work on an original material by editing and mixing, which yields to new creations. Greenhow et al. (2009) emphasize that publishing, sharing, and remixing content do not require a sophisticated technical expertise.

The use of Web 2.0 in education, especially in English Language Teaching, helps learners to use the language in an authentic context even if they don't have much chance to participate in natural environment for language acquisition. Addressing to an authentic audience is utilized through various tools on Web 2.0, which we can be named as social networking, blogging, RSS feeds, and wikis. As Web 2.0 tools allow users to create and share information and media in a global scale, students are no longer passive recipients of knowledge. Rather, they are active participants that create content by remixing original materials. Blogs, video-sharing sites, and 
other visual-sharing sites lead students to promote their products as well as being able to criticize what their friends have brought about (Baird \& Fisher, 2005; Crook \& Harrison, 2008).

\section{Corpus Studies and Learning Vocabulary on the Web}

Vocabulary studies have gained a new momentum with the advances in the digital world. The computers have enabled us to calculate the frequency of the use of vocabularies in context together with their collocations. We can reach a huge collection of corpus and conduct studies regarding the use of corpora in given contexts. This has triggered a considerable amount of corpus studies. Corpora provide empirical evidence about language use and show the interaction between lexis, grammar and semantics. This computer-readable data is really helpful in building dictionaries, grammar and teaching materials (Altay \& Tilfarlioglu, 2012; Stubbs, 2008).

Regarding the use of web-based platforms for vocabulary learning, Wong and Looi (2010) carried out a project with mobile-assisted authentic content creation. In their case studies, the writers presented mobile-assisted language learning that emphasizes learner-created content. In order to learn English prepositions and Chinese idioms, primary school students used their mobile devices to take photos in real life contexts in order to make sentences with words and idioms they have learned. This project showed the potential of transforming language learning into an authentic learning experience.

Another study by Lin, Hsiao, Tseng, and Chan (2014) investigated whether computer-assisted vocabulary learning is comparable with computer-free and individual learning in a junior high school in Taiwan. Students' vocabulary gains and their behavioral patterns were examined in this study. Their results demonstrated that learning English vocabulary collaboratively in a technology-enhanced classroom was really fruitful for the learners.

In addition to current studies, researchers in a Japanese university created an e-portfolio program which allowed learners to record and save the target words online. The interactive program helped learners to visualize, practice and use the words they came across on the web. Students in this research were very optimistic about such an application but they also stated that the pros and cons of using technology have to be kept in mind (Tanaka, Yonesaka, Ueno, \& Ohnishi (2015).

Vocabulary learning is a serious problem in language classes and it is one of the common concerns of instructors at Gaziantep University. It is an important problem as students have many difficulties while trying to learn new words. The result of this problem can be seen clearly from the vocabulary section grades of midterms. Although teachers spend a huge amount of time to teach vocabulary through reading and other activities, they still cannot make teaching vocabulary more appealing to students, and it stands as a big barrier between teacher and student to overcome this problem. Being a passive attendee in the classroom decreases students' interest in learning. In English preparatory classes where students are exposed to learn English approximately 25 hours a week, students lose their interest and enthusiasm against foreign language learning. Thus, it is very important to create alternative teaching styles for those students. EFL learners at Gaziantep University generally have problems with learning vocabulary. Although they learn grammar items very well, they are not very successful at learning vocabulary, which leads them to fail in midterms and finals as most 
parts of these exams consist of vocabulary knowledge. Considering these problems, following research questions have been stated about this issue:

1) Is there a significant difference on vocabulary learning of the experimental group trained by using Web 2.0 tools and the control group trained by following the traditional lecture-based curriculum?

2) What are the EFL learners' attitudes towards learning vocabulary by using Web 2.0 tools?

3) Do the EFL learners consider Web 2.0 tools useful as a supplement to English language learning?

\section{Methodology}

\section{The Research Design}

This is an experimental study supported with field notes and semi-structured interviews, in order to stable the triangulation of the study. In the beginning of the study, both groups were given a pre-test for the availability of a treatment. After that the experimental group received a treatment by using Web 2.0 tools in order to learn the target vocabularies while following the curriculum. The treatment was applied for two hours per week and lasted for twelve weeks. The control group didn't receive any treatment but attended the lecture-based instruction as usual in order to learn the target vocabulary. At the end of the study, a post-test was given to both groups to see if there was a meaningful difference between control group and experimental group. Immediately after the post-test, semi-structured interviews were carried out with students in the experimental group in order to learn their views and opinions for the study. Also, field notes were taken to identify the problems and the difficulties during this process.

Table 1. The Research Design

\begin{tabular}{|llllll|}
\hline Groups & Step 1 & Step 2 & Step 3 & Step 4 & Step 5 \\
\hline $\begin{array}{l}\text { Experimental } \\
\text { Group }\end{array}$ & Random & Pre-test & Treatment & Post-test & $\begin{array}{l}\text { Interviews } \\
+ \text { Field }\end{array}$ \\
Assignment & & & & Notes \\
Control Group & $\begin{array}{l}\text { Random } \\
\text { Assignment }\end{array}$ & Pre-test & --- & Post-test & -- \\
\hline
\end{tabular}

\section{Participants}

This study was conducted at the English preparation classes of the School of Foreign Languages at Gaziantep University. The experimental group consisted of 23 students (10 female-13 male). Their ages were between 18 and 23, with an average of 19. In the control group, there were 22 students ( 8 females- 14 males) and their ages were between 18 and 24 with an average of 20. Participants of each group were placed heterogeneously according to their departments. Their departments included mostly Faculty of Engineering (Electrical \& Electronics, Food, Industrial, Civil and Physics) and Faculty of Medicine. 


\section{Procedures}

The treatment session in this study consisted of learner-created content based on the upcoming vocabularies during the semester. Learners created, edited and shared their works on virtual classroom by using social networking sites. In order to carry out the treatment, the researcher prepared an agenda to cover expected 500 vocabularies in three months. First of all, the students were divided into groups of four, and each group was assigned with ten vocabularies per week. After that, the researcher created a special group on Facebook where only group members can interact with each other. All students enrolled in this group so as to create a virtual classroom environment. The wall feature in the group allowed members to share their presentations, videos, photos and other documents. Members could see others' posts and they could comment and share their opinions with each other. During the threemonth treatment, the researcher asked the students to cover four assignments. Table 2 shows the agenda for the treatment.

Table 2. The Assignments of the Students

\begin{tabular}{|ll|}
\hline Topics & Tasks \\
\hline 1- Facebook & $\begin{array}{l}\text { Preparing and publishing presentations: For this task, you need to } \\
\text { prepare presentations and share them on Facebook group. You } \\
\text { need to use different multimedia sources which include the target } \\
\text { vocabularies you are expected to present to other group } \\
\text { members. } \\
\text { 2- Blogs } \\
\text { Creating e-portfolios on Blogs: You need to create a blog for your } \\
\text { group members. You need to make up stories about your } \\
\text { assigned words. You can also use other entries on the web and } \\
\text { edit them. Each group member has to make at least three } \\
\text { entries. Please share the link of your blog on Facebook group. } \\
\text { 3- Word Exercise } \\
\text { Pour target words by giving their definitions, example sentences, } \\
\text { synonyms and antonyms together with other any interesting } \\
\text { information about these words. You also need to prepare a small } \\
\text { quiz which can include multiple choice questions, sentence } \\
\text { completion, etc. } \\
\text { Creating and editing Wiki services: You need to edit or create } \\
\text { three different texts. First one should be on Wikipedia for } \\
\text { explanatory information. The other one should be on Wikitravel } \\
\text { for giving tips for tourists in your hometown. And the last one } \\
\text { should be on Wikihow for explaining a procedure for something } \\
\text { (such as your favorite dish). }\end{array}$ \\
\hline 4- Wiki Services &
\end{tabular}

As a first assignment, the students were expected to prepare PowerPoint presentations. Their presentations included pictures, songs and video clips containing the target vocabularies. YouTube was especially useful for reaching songs and video clips. The products were published on virtual classroom. Second assignment was about creating e-portfolios. The learners created 
blogs and were asked to make up stories including the target words. They also edited and rewrote interesting stories to highlight their assigned vocabularies. The students also shared their writing assignments and learner profiles on the blogs. Another assignment was to create vocabulary exercises. The researcher asked each group to include definitions of the vocabularies, example sentences, synonyms and antonyms and other supportive materials. The exercises consisted of multiple choice questions, sentence completions and inferring the word from the context. The last assignment was about creating and editing various Wiki services. These included Wikipedia, for entries about general topics; Wikitravel, for creating entries about their hometowns as a guide for tourists; Wikihow, for explaining procedures about how to do something.

\section{Instruments}

A multiple choice vocabulary test was used as a pre-test and post-test instrument for the experimental and the control group. The test consisted of 40 items with four choices for each item and it aimed to test students' vocabulary knowledge at recognition level. While preparing the tests, the target vocabularies were chosen randomly among the vocabularies that the groups were going to learn in next three months in the second semester. In order to ensure the validity of the vocabulary test, the researcher co-operated with the consultants at the testing and the evaluation office and created the test together. The reliability of the test was analyzed in SPSS and the Cronbach's Alpha value was found as 0.69; that is, the test was reliable and had relatively sufficient internal consistency.

Having implementing the post-test, semi-structured interviews were conducted with 18 students in the experimental group regarding their attitudes towards the use of web-based platforms for improving their vocabulary knowledge. The interview questions were prepared with a consultant in order to ensure the validity. Before conducting the interviews in the experimental group, the interview questions were applied to two independent groups in order to see if both groups understand the same thing from the questions. A voice recorder and a transcription notebook were used to record and to transcribe the answers.

After that, the researcher took field notes from the beginning of the experiment to the end in order to reflect the challenges he came across while integrating the online platforms into the classroom environment. The field notes were intended to pave the way for the teachers and the researchers who wanted to integrate social networking into their classrooms

\section{Data Collection and Analysis}

The experimental phase of this research lasted for twelve weeks. The midterm exam was held at the end of the first semester. The pre-tests were applied to the assigned groups in February and the post-tests were applied at the beginning of May. The Independent Sampled t-test was applied to the results in order to see whether there was a statistical difference resulting from the treatment between the groups. SPSS 15.0 program was used to analyze the data. The field notes were also taken throughout the treatment period. Semi-structured interviews were conducted immediately after the treatment. Some of the interviewees' views were transcribed and others are taken as notes in order to learn their attitudes towards the implication of the treatment. Following questions were asked to elicit their views: 
1) What do you think about our activities on social media to learn vocabulary?

2) What are the main strengths of the activities?

3) What are the points you consider weak and needs to be supported?

\section{Findings}

\section{Analysis of the Pre-test, Midterm 1, and Post-test Results}

\section{Statistical Analysis of the Pre-test Results}

In order to assess the prior knowledge of the target words, the researcher applied a pre-test both to the control group and the experimental group. The pre-test result aimed to show whether there was a significant difference regarding prior vocabulary knowledge between the groups. To be able to observe any meaningful change after the treatment, the vocabulary knowledge of the groups had to be at the same level. The mean scores, standard deviation, $t$ and $p$ values between the groups were analyzed. Table 2 demonstrates the results of the pretest:

Table 2. Pre-test Mean Scores, Standard Deviation, Degrees of Freedom, $t$ and $p$ Values for the Experimental and the Control Groups

\begin{tabular}{|lllllll|}
\hline Groups & N & Mean & Sd. & df & t & p \\
\hline $\begin{array}{l}\text { Experimental } \\
\text { Group }\end{array}$ & 23 & 13.13 & 4.29 & & & \\
Control Group & 22 & 13.55 & 3.36 & & -0.36 & .267 \\
\hline
\end{tabular}

The statistics in Table 2 illustrates that there was not much variation between the mean scores of the experimental group and the control group. The $p$ value $[p>0.05]$ indicates that there is no statistically significant difference between the two groups. The vocabulary knowledge of both groups is almost at the same at recognition level. This equity probably results from the fact that at the beginning of the academic span, all students were placed into the group levels according to their results from the proficiency exam. Both groups have been following the same curriculum and no treatment had been applied. The pre-test results indicate that both groups are available for an experimental study.

\section{Statistical Analysis of the Midterm 1 Results}

After the proficiency exam, the level-based classes were formed according to students' score/grades. Two months after the proficiency exam, all groups took Midterm 1. As an additional support to the pre-test findings, the table below shows statistical findings for the Midterm 1 results for both groups. 
Table 3. Midterm 1 Mean Scores, Standard Deviation, Degrees of Freedom, $t$ and $p$ Values for the Experimental and the Control Groups

\begin{tabular}{|lllllll|}
\hline Groups & N & Mean & Sd. & df & t & p \\
\hline $\begin{array}{l}\text { Experimental } \\
\text { Group }\end{array}$ & 23 & 71.84 & 13.07 & & & \\
Control Group & 22 & 70.82 & 12.05 & & & 0.27 \\
\hline
\end{tabular}

Table 3 shows that there is not much difference in mean scores of both groups. Here, the significant values [ $t=0.27$ and $p>0.05$ ] depicts that there is not a statistically significant difference between the Midterm 1 results analyses of the groups. It can be said that this is due to the fact that having been replaced after the proficiency exam; the groups received no treatment and had been following the same curriculum until Midterm 1.

\section{Statistical Analysis of the Post-test Results}

At the end of the treatment, the researcher applied the post-test to the experimental and control group to find out whether using Web 2.0 tools with the experimental group has had a statistically significant difference in terms of vocabulary knowledge compared with the control group that merely followed the curriculum. The treatment lasted for three months and during this time, the control group was taught the same vocabularies as well. Table 4 shows the analyses of the post-test results.

Table 4. The Post-test Results for the Experimental and the Control Groups

\begin{tabular}{|lllllll|}
\hline Groups & N & Mean & Sd. & df & t & p \\
\hline $\begin{array}{l}\text { Experimental } \\
\text { Group }\end{array}$ & 23 & 23.17 & 5.27 & & & \\
Control Group & 22 & 17.5 & 5.21 & & & \\
\hline
\end{tabular}

The post-test results show that there is a difference between mean scores of the experimental group and the control group, and this difference is statistically significant. The $p$ value $[p<$ $0.05]$ indicates the change between the test results. This difference probably resulted from the fact that the experimental group received a treatment while the control group just followed the curriculum.

The statistically significant difference on the experimental group may have resulted from assigning them the vocabularies in groups. The students in the experimental group were formed as groups of four in order to present the vocabularies that were assigned to them regularly. Studying cooperatively with group members is probably one of the most important factors for the gains during treatment phase. Each time the researcher tried to form groups as heterogeneous as possible to lead students help each other. The group members worked together for their products, and all groups were able to see the posts from other groups within Facebook group which also allowed the researcher to track who has seen the posts.

Table 5 shows the pre-test and the post-test scores of both groups to compare the mean differences before and after the treatment. 
Table 5. The Comparison of the Mean Scores between the Experimental Group and the Control Group

\begin{tabular}{|lllllll|}
\hline Test & \multicolumn{2}{l}{ Experimental Group } & \multicolumn{4}{c|}{ Control Group } \\
Results & $\mathbf{N}$ & Mean & SD & N & Mean & SD \\
\hline Pre-test & 23 & 13.13 & 4.29 & 22 & 13.55 & 3.36 \\
Post-test & 23 & 23.17 & 5.27 & 22 & 17.5 & 5.21 \\
\hline
\end{tabular}

It can be seen from the Table 5 that while the mean of the pre-test was 13.13 , the post-test mean showed that it increased to 23.17 in the experimental group. On the other hand, the pre-test mean of the control group was 13.55 and the post-test indicated that it increased to 17.5 showing that they had gains as well. We can see that there is an increase in the mean scores of the both groups. However, the mean post-test score of the experimental group has a meaningful difference when it is compared with that of the control group. This may have resulted from the treatment that was applied to the experimental group.

The Figure 1 shows an illustration of the increase within the groups:

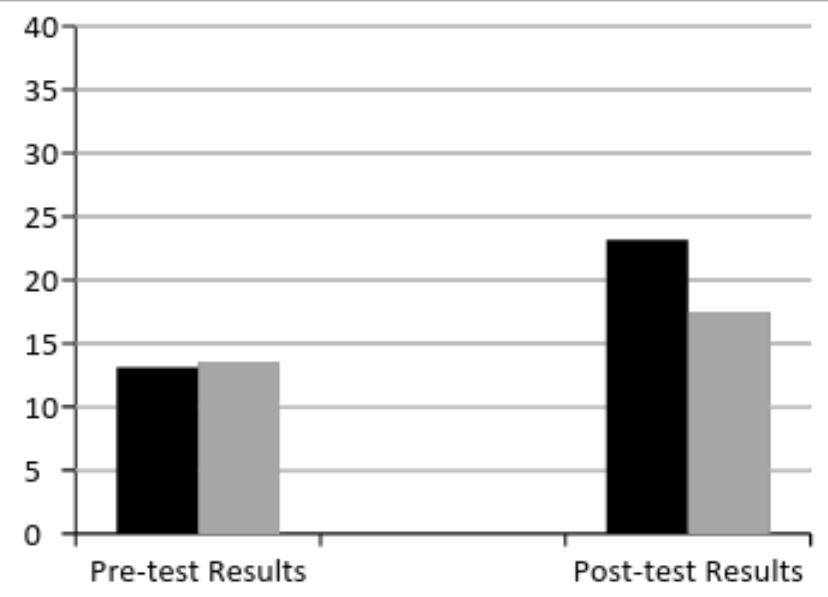

Experimental Group Control Group

Figure 1. The Mean Scores of the Experimental and the Control Group before and after the Tests

It can also be seen from the Figure 1 that the control group also had gains without a treatment but we can say that this is less than they were expected to learn. The reason of this may be that usual classroom-based vocabulary learning becomes monotonous after a while and students try to cope with hundreds of vocabularies that must be learned.

\section{Analysis of the Semi-Structured Interviews}

Having conducting the post-test, the researcher carried out semi-structured interviews with 18 students willing to take part in this phase of the study. The transcriptions and the notes were analyzed and the main themes and the codes were identified. Vocabulary learning on Web 2.0 tools and Language learning on Web 2.0 tools were identified as two main themes of the interviews. Under the theme of Vocabulary learning on Web 2.0 tools, common opinions were 
coded as Facilitator for vocabulary learning, Entertaining, Group-work and Continuity. On the other hand, under the theme of Language learning on Web 2.0 tools, common opinions were coded as Efficacy, and Negative comments. The Table 6 shows the themes and the codes of the interviews.

Table 6. The Themes and the Coding of the Interviews

\begin{tabular}{|lll|}
\hline Themes & Vocabulary Learning on Web 2.0 tools & $\begin{array}{l}\text { Language Learning on Web 2.0 } \\
\text { tools }\end{array}$ \\
\hline Coding & Facilitator for Learning & Efficacy \\
& $\begin{array}{l}\text { Entertaining } \\
\text { Group-work } \\
\text { Continuity }\end{array}$ & Negative Comments \\
\hline
\end{tabular}

\section{Theme 1: Vocabulary Learning on Web 2.0 Tools}

Findings for the interview question 1 suggest that almost all students consider Web 2.0 tools very useful for improving their vocabularies. A total of 16 students out of 18 agree on this point.

\section{Facilitator for Vocabulary Learning}

In terms of vocabulary learning, Web 2.0 tools are considered as very important facilitators by students. They think that it is easier to learn words on social networking sites. The interviewee, numbered as 10, points out this issue as follows:

Of course, the activities on social networking sites were very useful for me. I have a lot of difficulties when I try to memorize words. For that reason, having such alternatives is very good. These activities help me to remember simple but important words easily. You know learning English generally means memorizing new words and these activities make it easier to learn. Thus, I think that we should do such activities more.

Another interviewee (no:3) shares similar opinions and reflects how some special features on Facebook help him to learn:

In my opinion, this is a nice activity. I believe it is very useful for me because sometimes- not sometimes actually many times, I forget the words that we learnt at the school. I often log on our group on Facebook and check the new words there. Additionally, one another point that I consider helpful is the opportunity to be able to comment on the posts and keep in touch with our friends. Sir, I also have a suggestion that I forgot telling you. I just remembered it. Why don't we make competitions for vocabularies and grammar on those tools? 
This student's opinions also support the general attitude towards social networking sites. Being able to comment on the posts also make it attractive and entertaining for students. Comments on the wall are very important to foster collaborative learning among students. They can ask questions about the topics covered during the lessons and get help from their peers without a need to teacher.

Constructivist approach focuses on the role of the learner during learning process. Learner becomes much more active rather than listening to the teacher silently. Interviewee (no:12) states this issue together with the importance of using visual elements:

I think it is helpful for improving our vocabulary knowledge. The presentations we shared and the blogs had both visual and textual elements and I think these are long lasting. Such activities help students learn the difficult vocabularies easily. The education in preparation class is not boring and student-centered. Such activities make students more active.

This comment also shows us a reflection on language learning in preparation class. Although the course books are mostly designed according to Communicative Language Learning, the communicative activities seem to be monotonous. Creating even simple presentations by students themselves makes them more active.

\section{Entertaining}

Students also find the activities on social networking sites very entertaining. Various comments on the posts, interesting photos about the topics and funny topics for learning all make those activities entertaining and appealing for students. Interviewee 11 specifies this entertaining role together with its reason:

Absolutely, they are helpful. These activities contributed to me a lot and I believe it will do much more soon. It is smart to use social networking for this aim; at least it helps some of my classmates be more responsible. Especially the topics on blogs are very interesting and entertaining. I had a lot fun while preparing blogs with my friends. I think we know that we won't be graded on these projects and this makes us more flexible to work on our topics.

Interviewee 11 mentions about the entertaining role for social networking sites together with their importance on collaborative learning. For him, not being graded from the work they are doing makes him to study in a more relaxing atmosphere. Thus, we can state that it is a better idea not to grade students from any work they do on those tools. Interviewee 4 also states this entertaining role of social networking sites:

In my opinion, all these activities on web are very helpful. My friends are always online and activities on Facebook are very useful as we check it many times to see what's new. Additionally, it is very entertaining. Learning while entertaining is both easier and more long-lasting.

We can infer that students check their Facebook accounts many times in a day and they are curious about seeing new posts on the wall. They can share funny things about learning English in the group and all members can share their opinions. 


\section{Group work}

While many students consider group-works to be fun and quite useful, there are also other students mentioned about some negative points which worth considering upon applying such activities. Interviewee 7 indicates this point:

For me, all the activities are useful. For example, when we try to prepare some materials, we spend time on those words and we remember them. However, in my opinion, we should not do activities in a group-work; at least, some of them, because it is common that the group members may not get on well with each other. Sometimes, one group member makes most of the effort and the others do not contribute a lot.

It is important to think carefully about the groups that the teacher is going to form. Some group members may not get on well with others and this may result in lack of devotion to the product they are creating together. Additionally, English level of one group might be too low or reverse. Thus, the teacher needs to form groups more heterogeneous. This can be done by changing the group members for each activity. From this point of view, interviewee 9 also expresses her feelings: "Using social networking is really great but I think activities must be individual. I think I forget the vocabularies on other group works."

Most of the students $(16 / 18)$ consider the activities useful but this student's comment also enlightens one part. The activities done by one group may not be given necessary attention by other groups. Thus, wrap-up activities can be useful to avoid such conditions.

\section{Continuity}

One another coding common among the students is about the continuity of activities. Although students prepared almost all the materials themselves, it can be said that they enjoyed producing something and wanted such activities continue. Interviewee 17 reflects his views on this point: "All activities we did on the web were very useful in terms of enriching my vocabulary knowledge. Especially I liked working on blogs. In my opinion, we have to do much more similar activities. Even, we need to support them with extra videos and music."

This student stated his opinion about the continuity of these activities and this reflects the view of other 11 interviewees who also stated the importance of the continuity of these activities. This probably results from the fact that there was not any similar activity during the first semester as the treatment was applied in the second semester. Additionally we can infer that since vocabulary is important to be successful, supporting their vocabulary knowledge is both useful and entertaining, and for that reason, they wanted to continue these activities.

\section{Theme 2: Language Learning on Web 2.0 Tools}

The analyses of the interviews suggested language learning on Web 2.0 tools as another theme together with vocabulary learning. The activities on Web 2.0 tools were mostly about vocabulary teaching, but they contributed to the language learning as well. Videos, music, 
cartoons and many other materials that the teacher and students share on the virtual classroom -closed Facebook group- helped students to improve their language skills. A total of 16 students, who favored vocabulary learning on those tools, also favored language learning. Two students gave negative feedbacks and they are also important to keep in the mind for the future applications.

\section{Efficacy}

Besides vocabulary learning, the use of Web 2.0 tools is also useful to improve other skills like listening and reading since many activities are supported with media files. Our digital native students spend a lot of time in front of computers and using social media for language education is considered very beneficial. Interviewee 15 tells her opinions on this issue:

Now we can do most of our work on the web. Personally, I spend hours and hours on the web every day and while I am surfing, I read a lot of articles and watch many interesting videos. Social networking is part of our everyday life. Whenever I see a new word on a video or sentences that I don't understand, I check their meanings. They all help me to learn new things and repeat my previous knowledge. Not only I improve my English, but also I improve myself on other topics.

Interviewee 15 describes how much time she spends in front of a computer. At this point, the videos we shared on our virtual classroom via YouTube are liked a lot by the students. Many times they ask for meaning of some phrases or try to capture the sentences in a different accent. Interviewee 12 also finds social media useful and shares his views:

The use of social networking for language education is absolutely useful. Because we are living in a computer era and language education should not be limited within the classroom, we must support it with technology. Things that we learn on social networking are much more long-lasting as there are many audible and visual supports. I think we also need to use chat rooms more to improve our language.

Interviewee 12 agrees with interviewee 15 and this also reflects the opinions of other 16 students. Classroom-bound language learning can be quite boring when activities become routine. Many course books are supported with CD-ROMs and other technological materials but they don't allow learners to interact with each other and edit the context. Many computerassisted programs can be boring after a while because of repeated activities. However, Web 2.0 tools compensate this drawback thanks to their interactive nature, which keeps learners alert about the new notifications.

\section{Negative Comments}

Almost all students (16 out of 18 ) have a positive attitude towards language learning on Web 2.0 tools. However, two students do not appear to consider those tools as efficient. It is worth considering why they think them as useless in order to get a better picture about the weaknesses. Analysis of the transcriptions states that these negative feedbacks results from 
either those students do not use social networking sites as much as others or they did not like the activities done by their friends. One of the students shares his feelings as:

As far as I have observed, those kinds of activities are not useful and do not give expected outcomes. In my opinion, those social networking tools are not useful at all. I don't like spending time on social networking sites. Students are not looking for something to improve themselves on those tools and this is not an assumption, I am sure of this. Also, we need to consider what we expect from students while they are preparing some materials because there can be reactions for their products. We need to keep their English level in the mind and expect their best, not something over the clouds. We must be doing all these activities in a relaxing atmosphere, I mean, we should not be afraid of others to give negative reactions.

This student has a quite different comment from the rest of the class and the reasons for such comments are various. As she has stated, she does not use social networking and doing an activity on a platform in which she does not have much experience might have led her to express those feelings. On the other hand, when this student presented her work on blog, it was apparent that she copied all the things on Wikipedia and pasted them on her blog. Additionally, when other students asked for the meaning of some words, which are far above their English level, she did not give an answer. This can be the reason for reactions from other students against her. Thus, we can say that while assigning any activity, we may not make it compulsory for students to present their works. This view correlates with the comments from interviewee 11 about not being graded from those activities. If the teacher makes it compulsory and grades students from the products they have made, this may destroy the entertaining value of those tools and may reduce the relaxing atmosphere.

\section{The Field Notes}

The researcher came across with some important difficulties before and while implementing the treatment. The first problem was about the number of the students joined the virtual classroom on Facebook. As it was not compulsory, 16 students out 23 became members of the group and this was not enough to do an activity on Facebook and conduct the backbone of the treatment as only Facebook integrated "Seen by..." function which informed everyone whether they saw the posts or not. However, this problem was solved in a couple of weeks because when the activities were started, the others also became members one by one.

Another problem arose with the use of mother tongue. At the beginning of the treatment, the teacher did not mention about any restrictions regarding the use mother tongue. However, this led some unwanted behaviors. On some topics, students were commenting in Turkish and this created some arguments among students. If the researcher had not avoided those arguments, they might have ended up with bigger problems. Thus, it is important to prohibit using mother tongue on social networking sites.

Some students continuously complained about their group members. In this case, there is not absolute solution because there is no way to please every student. As Richards and Rogers (2011) have stated, group formations have to be heterogeneous in order to reach expected gains. Thus, appointing the group members can be a problem but this can be overcome by changing group members with every new activity. 


\section{Discussion}

Findings of this study show that social networking sites are useful as a facilitator for vocabulary learning. Using visual, textual and audible materials on the web helps students focus on the target words easily. Language learning on the web can be a useful supplement to the classroom teaching as students also take an active role by creating the content themselves. Interviews also reveal that doing these activities is not a burden for them; rather it is an entertaining way to learn something. Additionally, it is notable to point out the fact that the teacher shares the responsibilities of teaching in a less stressful and more enjoyable way. Vocabulary learning, a point in which the teacher does not have much control to help students overcome difficulties, becomes much more efficient when teaching shifts from teachercentered into student-centered approaches. This gives students a sense of responsibility for their learning, which is also aim of creating autonomous learners.

Another important point is that students are willing to continue activities on Web 2.0 tools. They enjoyed creating content on their own and sharing them with their friends. Some group members might not get on well with each other but this can be minimized by changing group members each time. Negative comments also enlighten us about keeping in the mind that there might be students who do not enjoy spending time on the web. Thus, we need to give accessible assignments for every student.

Findings of the experimental phase of this research are parallel with findings of the study by Horst, Cobb, and Nicolae (2005) who intended to expand academic vocabulary with an interactive online database. Both experimental studies have shown the treatments applied to the experimental groups to expand vocabulary have proven themselves feasible. Another research by Lin et al. (2014) showed that using technology in a collaborative environment for learning vocabulary at recognition level is useful.

Yet another experimental research by Monica-Arina and Anamaria-Mirabela (2014) aiming at teaching vocabulary on Facebook to a much larger learners $(n=127)$ does not support findings of our study. It was found that both experimental and control groups had gains and the former outperformed the latter but this difference was not statistically significant.

Findings of the semi-structured interviews concur with many other studies that expected to get students' attitudes toward Web 2.0 tools. The studies by Chan and Cmon (2009), Piriyasilpa (2011), and Eren (2012) suggest that learners have positive attitudes towards language learning on Facebook and Blogs. Those studies indicate that collaboration among students was useful to create social networks and it was also beneficial for supporting language learning.

\section{Conclusion}

The rapid change shows its effects on today's digital native students. We have a generation of students surrounded with mobile tools that keep them online every time. They are born into this technology, and social relations are now continuing on social networking sites that help them share their life online with their friends. In terms of teachers, however, this transition is not so quick and adapting this technology is not easy as well. There has always been a generation gap with teachers and students but astonishing changes in lifestyles has made this gap bigger and bigger day by day. Today, it is not compulsory to use Web 2.0 tools in language 
education but when we look at the current developments in education and think about the future, it wouldn't be a presumptuous claim to say that classroom borders will become lighter and students will take care of their learning much more compared with previous decades.

The present research was conducted with adult learners at the university level. A similar study needs to be carried out at high school level in order to see if a similar study with high school students can be useful. It is not recommended to conduct a similar study at primary school level as teacher-student interaction may not go on as smoothly as intended on social networking sites. Another crucial point to be investigated is the faculty attitudes towards using Web 2.0 tools for language teaching. In order to keep up with digital native students, faculty opinions are very important to evaluate to create awareness for the use of Web 2.0 tools as facilitator for language teaching.

All in all, considering those points, this research suggests that applying Web 2.0 tools into the classroom is easy and feasible. It is useful for students and they enjoy while they are preparing content for their own learning, which also helps them to have more responsibility for their own learning. Also, such implementation is not a heavy burden for teachers. After dividing groups and giving their assignments, teachers just need to lead as guides or counselors. The widening gap between teachers and learners can be overcome by making classes much more appealing for learners.

\section{References}

Akcay, A. \& Arslan A. (2010). The using blogs in Turkish Education. Procedia Social and Behavioral Sciences, 2(2), 1195-1199.

Altay, M. \& Tilfarlioglu, F. Y. (2012). Building up a learner corpus through creative nonfiction prose: an experimental research. Electronic Journal of Social Sciences, 11(39), 22-35.

Baird E \& Fisher M. (2005). Neomillennial user experience design strategies: Utilizing social networking media to support "always on" learning styles. Educational Technology Systems, 34(1) 5-32.

Chan, C. \& Cmor, D. (2009). Blogging toward information literacy: Engaging students and facilitating peer learning. Reference Services Review, 37(4), 395-407.

Cormode, G. \& Krishnamurthy, B. (2008). Key differences between Web 1.0 and Web 2.0. First Monday, 13(6). Retrieved on 1 July 2015 from http://firstmonday.org/article/view/ $2125 / 1972$

Crook, C. \& Harrison, C. (2008, September). Web 2.0 technologies and learning at key stages 3 and 4: Summary report. Retrieved on 1 July 2015 from http://dera.ioe.ac.uk/1480/1/ becta_2008_web2_summary.pdf

Cullen, R., Kullman, J., \& Wild, C. (2013). Online collaborative learning on an ESL teacher education programme. ELT Journal, 67(4), 425-434.

Eren, Ö. (2012). Students' attitudes towards using social networking in foreign language classes: A Facebook example. International Journal of Business and Social Science, 3(20), 288-294. 
George, D. R. \& Dellasega, C. (2011). Use of social media in graduate-level medical humanities education: Two pilot studies from Penn State College of Medicine. Medical Teacher, 33(8), 429-434.

Greenhow, C., Robelia, B., \& Hughes, J. (2009). Learning, teaching, and scholarship in a digital age: Web 2.0 and classroom research: What path should we take now? Educational Researcher, 38, 246-259.

Horst, M., Cobb, T., \& Nicolae, I. (2005). Expanding academic vocabulary with an interactive online database. Language Learning \& Technology, 9(12), 90-110.

Lee, L. \& Markey, A. (2014). A study of learners' perceptions of online intercultural exchange through Web 2.0 technologies. ReCALL, 26(03), 281-297.

Lin, C. C., Hsiao, H. S., Tseng, S. P., \& Chan, H. J. (2014). Learning English vocabulary collaboratively in a technology-supported classroom. Turkish Online Journal of Educational Technology, 13(1), 162-173.

Mason, R. (2006). Learning technologies for adult continuing education. Studies in Continuing Education , 28(2) 121-133.

McKeown, M. G. (1985). The acquisition of word meaning from context by children of high and low ability. Reading Research Quarterly, 20(4), 482-496.

Means, B., Toyama, Y., Murphy, R., Bakia, M., \& Jones, K. (2009). Evaluation of Evidence-Based Practices in Online Learning: A Meta-Analysis and Review of Online Learning Studies. US Department of Education. Retrieved on 1 July 2015 from https://www2.ed.gov/rschstat/ eval/tech/evidence-based-practices/finalreport.pdf

Monica-Ariana, S. \& Anamaria-Mirabela, P. (2014). The impact of social media on vocabulary learning case study Facebook. Annals of the University of Oradea, Economic Science Series, 23(2), 120-130.

Nation, I. S. P. (1990). Teaching and learning vocabulary. Rowley, MA: Newbury.

O'Reilly, T. (2005). What is Web 2.0: Design patterns and business models for the next generation of software. Retrieved on 1 July 2015 from http://oreilly.com/web2/archive/ what-is-web-20.html

Prensky, M. (2001). Digital natives, digital immigrants. On the horizon, 9(5). 1-6.

Piriyasilpa, Y. (2011). See you in Facebook: The effects of incorporating online social networking in the language classroom. Journal of Global Management Research.67-80. Retrieved on 1 July 2015 from http://gmrjournal.uqam.ca/documents/GMRJ-V7N1JUN2011-67-80.pdf

Richards, J. C. (1976). The role of vocabulary teaching. TESOL Quarterly, 10(1), 77-89.

Richards, J. C. \& Rodgers, T. S., (2001). Approaches and methods in language teaching. New York: Cambridge University Press.

Stubbs, M. (2008). Language corpora. In A Davies \& C. Elder (Eds.), Handbook of applied linguistics (pp. 106-108). New York: John Wiley \& Sons.

Tanaka, H., Yonesaka, S. M., Ueno, Y., \& Ohnishi, A. (2015). An e-portfolio to enhance sustainable vocabulary learning in English. European Association for Computer Assisted Language Learning, 23(1), 41-58.

Thornbury, S. (2002). How to teach vocabulary. Boston, MA: Pearson Education. 
CONTEMPORARY EDUCATIONAL TECHNOLOGY, 2015, 6(4), 281-300

Wong, L. H. \& Looi, C. K. (2010). Vocabulary learning by mobile assisted authentic content creation and social meaning making. Journal of Computer Assisted Learning , 26, 421433.

Ziegler, S. (2007). The (mis)education of Generation M. Learning, Media and Technology, 32(1), 69-81.

Correspondence: Omer Eren, Lecturer, School of Foreign Languages, Gaziantep University, Gaziantep, Turkey 
Appendix:

Screen shots from students' works:

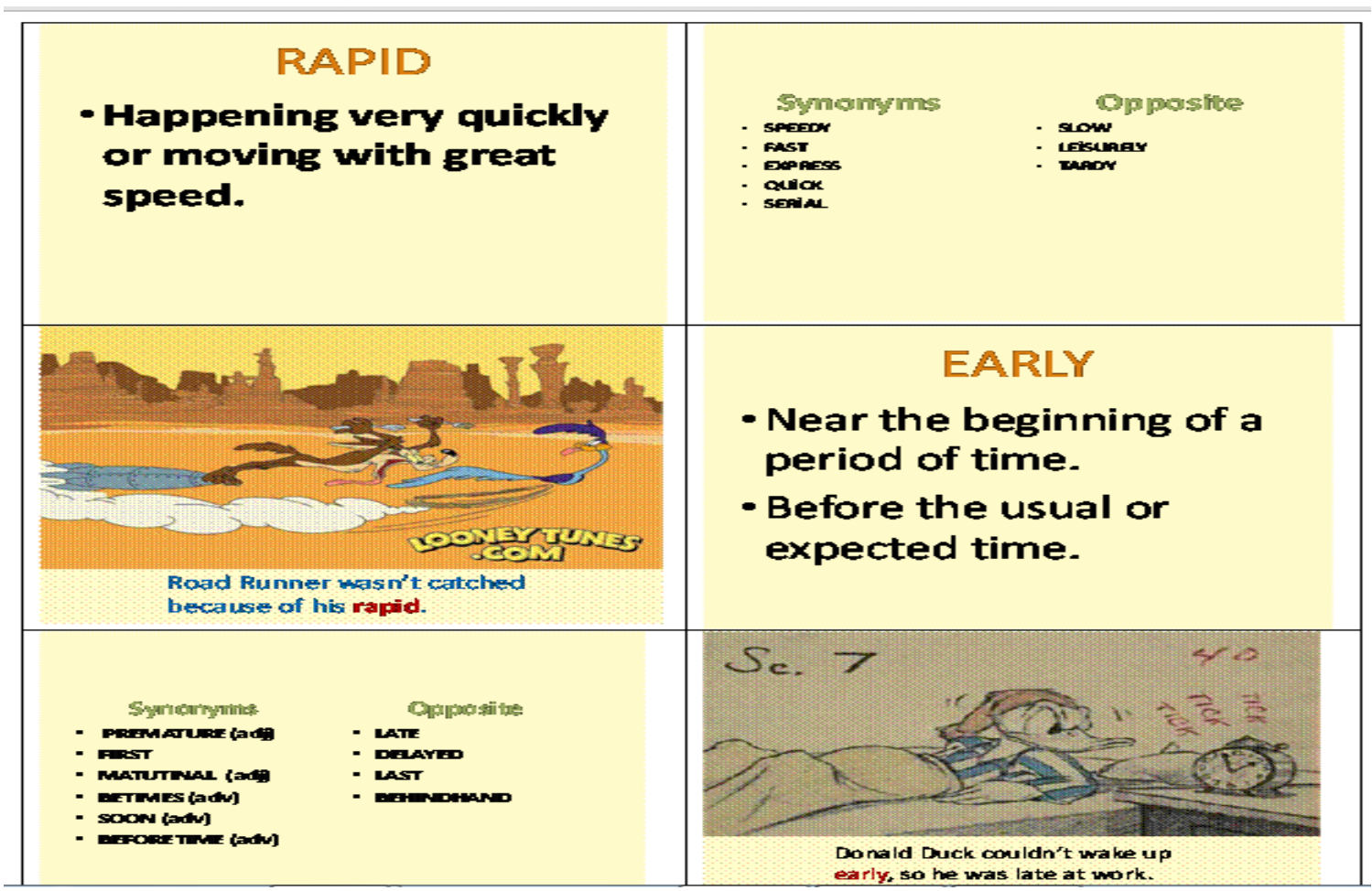

\section{THE AMISH}

Do you anything about Amish ? Now a days, it the most stronge religious group in the Worid. Amish was founded by Jacob Ammann who from in Switzeland at 16. centruies. Amish people accept basic Christian beliefs but also have some special interpretalions and emphases that have emerged throughout their history. They migrated from Europe to North America in the 18. and 19. centruies. They live technological country but they decline a technology. This do special them. Today, they live

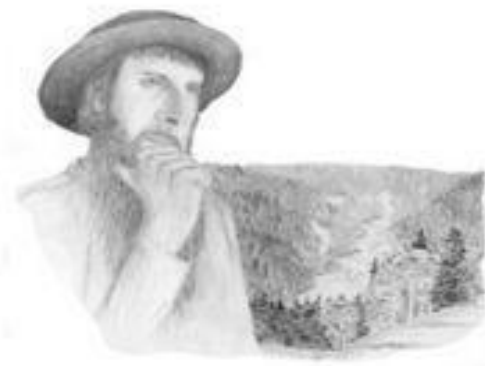

Jacob AMMENN in 463 geographical settlements in 30 states and the Canadian pravince of Ontario. Their population totals approximately 273,700 their unique practices make them one of American's the most interesting and colorful religious subcultures. We want to talk about Amish's family, education, dress and technology. 


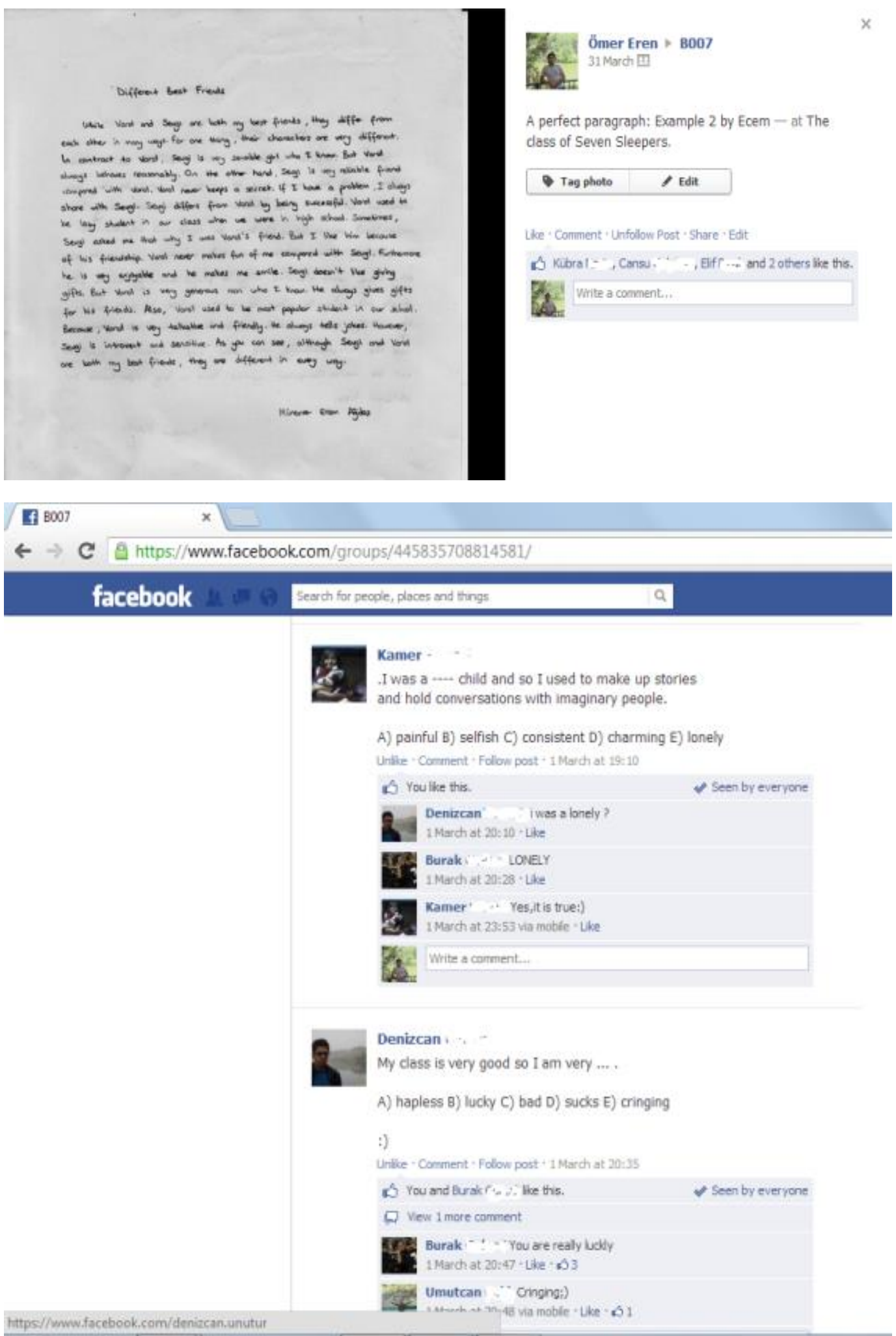

